
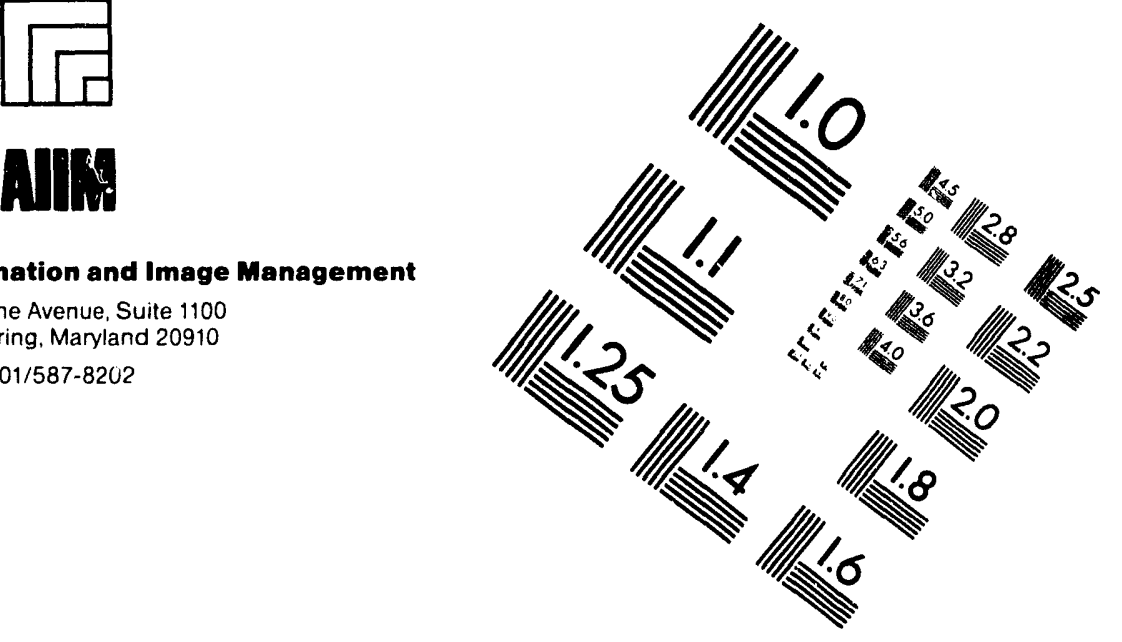

\title{
Centimeter
}

$\begin{array}{llllllllllllllll}1 & 2 & 3 & 4 & 5 & 6 & 7 & 8 & 9 & 10 & 11 & 12 & 13 & 14 & 15 & \mathrm{~mm}\end{array}$ Lul

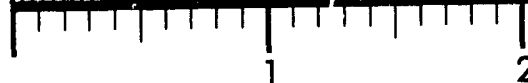

Inches
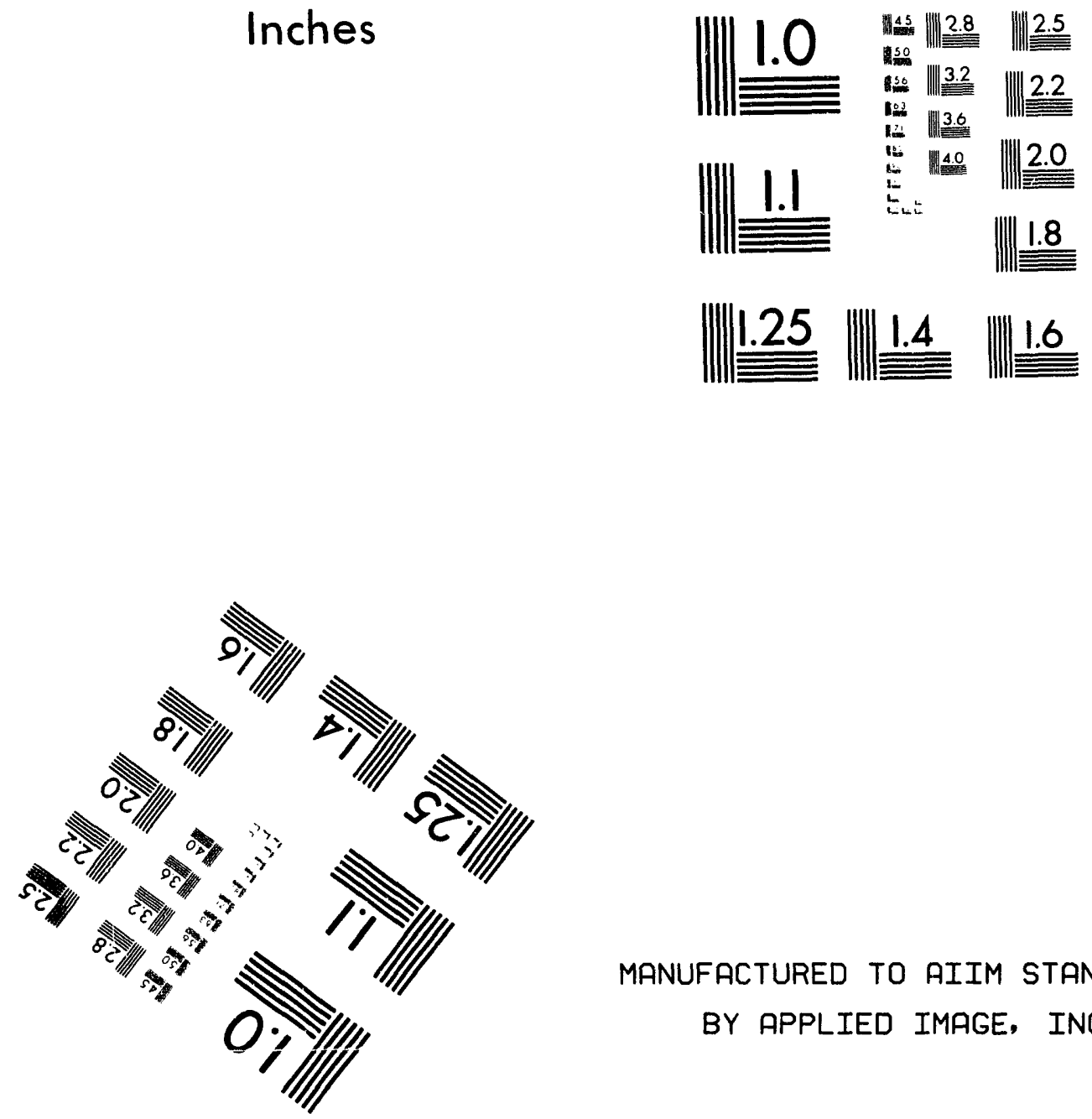

MANUFACTURED TO AIIM STANDARDS

BY APPLIED IMAGE, INC.

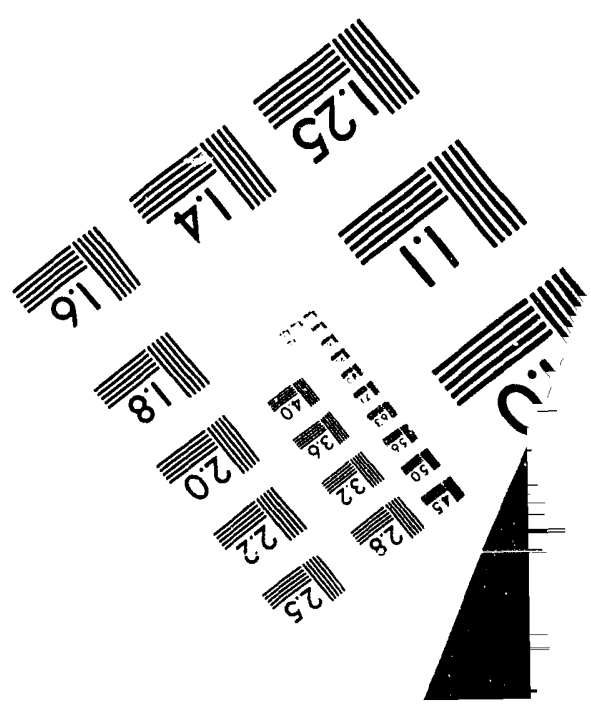



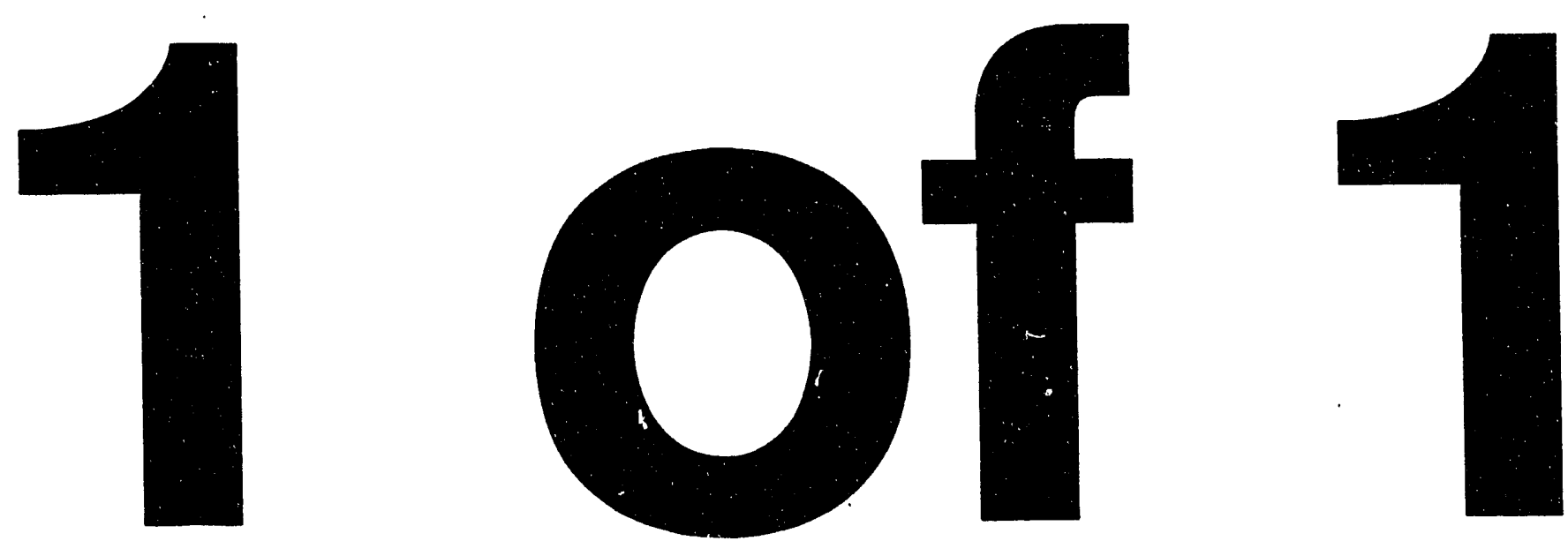


\section{THE EFFECTS OF RADIOLYSIS ON THE CORROSION AND STRESS \\ CORROSION BEHAVIOR OF 316 STAINLESS STEELS}

$$
\text { DCE } / E R / S 2.161 .5
$$

D.J. Duquette and D. Steiner

Rensselaer Polytechnic Institute, Troy, New York 12180

\section{SUMMARY}

This program is focused on the corrosion, stress corrosion and corrosion fatigue behavior of Type 316 stainless steel (316SS) at 50, 90, and $130^{\circ} \mathrm{C}$ in highpurity water. Irradiated solution tests are performed using high-energy photon radiation. The purpose of this work is to determine the effects of radiolysis products on the environmental stability of 316SS in support of the ITER first wall/shield/blanket design. Preliminary results suggest that irradiation of pure water at $50^{\circ} \mathrm{C}$ results in a shift in the electrochemical potential for $316 \mathrm{SS}$ of approximately $100 \mathrm{mV}$ in the active direction and nearly an order of magnitude increase in the passive current density as compared to non-irradiated conditions. This proposal outlines a three-year program to develop corrosion design criteria for the use of 316SS in an ITER environment.

\section{TECHNICAL PROGRESS REPORT}

Research performed during the first year of this project has focused on Type 316 austenitic stainless steel (316 SS) for use in the structural components of the water-cooled, ceramic breeder design for ITER. Of concern are the effects of gamma irradiation and the accompanying radiolysis products on the corrosion behavior and stress corrosion cracking susceptibility of 316 SS under conditions expected in the coolant of the ITER integral fi::st wall/shield/blanket. ${ }^{1}$

$316 \mathrm{SS}$ in the solution annealed (SA) condition, the reference alloy for the ITER CDA (Conceptual Design Activity) design is being examined. ${ }^{1}$ As welding 
will be performed extensively in fabrication, sensitized material is also being used in stress corrosion cracking (SCC) experiments.

The work has been directed toward building a data base of electrochemical measurements in irradiated and non-irradiated pure water at 50,90 , and $130^{\circ} \mathrm{C}$. Additional work with a radiolysis code has been completed, stress corrosion cracking tests are underway, and irradiated solution modeling is near completion.

The majority of the electrochemical work to date has been performed at $50^{\circ} \mathrm{C}$. SA $316 \mathrm{SS}$ has been tested in pure de ionized water with $0.0005 \mathrm{M} \mathrm{K}_{2} \mathrm{SO}_{4}$ as the 'reference solution'. The addition of potassium sulfate is necessary in order to provide solution conductivity for electrochemical measurements. Hydrogen, and in some cases argon, was used as a cover gas to aeaerate the solutions. Electrochemical tests included open circuit electrochemical potential (ECP) measurements, potentiodynamic anodic polarization scans, and fixed-potential passive current density tests.

Irradiated solution tests were performed at the RPI Linear Accelerator, which produced gamma radiation of $20 \mathrm{MeV}$ average energy at approximately 340 $\mathrm{kRad} /$ hour. The irradiated solution condition was studied at $50^{\circ} \mathrm{C}$. Solution irradiation under hydrogen cover gas resulted in approximately a $100 \mathrm{mV}$ active (negative) shift in the open circuit ECP. This active shift was attributed to a net increase in the reducing power of the solution, by the production of reducing radiolytic species. Based upon comparison of the ECP shift with other work in gamma radiation fields, this active shift is not expected to result in increased SCC susceptibility. It is important to note that the hydrogen content in this work was about $1500 \mathrm{ppb}$ (for 1 atm cover gas).

Anodic polarization tests in irradiated solution also revealed the active potential shift, shown in Figure 1, as well as nearly an order of magnitude 
increase in the passive current den ty as opposed to un-irradiated conditions. This passive current density increase could be considered a ten fold corrosion rate increase, raising the potential for safety concerns associated with activated corrosion product releases. Additional tests with platinum electrodes have led to the conclusion that the passive current density increases were due to surface oxidation reactions involving reducing species as well as to increased corrosion rates. Further irradiated and un-irradiated tests for passive current density have been performed, using the passive current density - time technique. The ECP was fixed in the passive potential range and the current density was measured with time. Figure 2 shows the resulting response, with the irradiated solution test exhibiting a higher steady state current density. However, the total charge in coulombs, the integrated area under the curve, was only $10 \%$ greater for the irradiated case. Since the surface reaction contribution of radiolytic products to passive current density is substantial ${ }^{2}$, the increase in corrosion rate is not considered to be significant.

Several slow strain rate test (SSRT) experiments of 316 SS wire have been completed in air at $25,50,90$, and $130^{\circ} \mathrm{C}$ and in the reference solution at $50^{\circ} \mathrm{C}$. The aqueous tests were conducted in a recirculating system with either hydrogen or argon deaeration. Electrochemical apparatus allowed for open circuit ECP measurement or fixing of potential during the in-solution tests. Both SA and sensitized (Sen.) samples have been tested.

All 316 SS wires were initially solution annealed at $1060^{\circ} \mathrm{C}$ for 0.5 hour and water quenched. Furnace sensitization heat treatment was carried out at $650^{\circ} \mathrm{C}$ for 2 hours/air cool followed by $650^{\circ} \mathrm{C}$ for 24 hours/air cool. Samples were mechanically polished to a 600 grit finish. The critical data collected in the SSRT experiments were elongation to failure (\% elongation) and the tensile strength. (Lower \% elongation compared to air test values indicates SCC susceptibility.) 
Quantitative examinations of the fracture surfaces is currently being performed. SSRT data in air lias been documented and were used for comparison to aqueous tests. The results of the SSRT tests performed to date are presented in Figures 3 and 4. The trend of decreasing tensile strength in air with increasing temperature corresponds to handbook data for stainless steel. Tests at $50^{\circ} \mathrm{C}$ in deaerated reference solution show no significant difference between hydrogen and argon as cover gas, for both SA and Sen. 316 SS samples. The \% elongation values for SA 316 SS tests in reference solution are slightly lower than those observed in air. The Sen. 316 SS results obtained in reference solution are nearly identical to the \% elongation in air. These results indicate that $316 \mathrm{SS}$ is not susceptible to $\mathrm{SCC}$ in deaerated pure water at $50^{\circ} \mathrm{C}$, for either the annealed or the sensitized microstructure.

SSRT experiments are continuing at 50 and at $90^{\circ} \mathrm{C}$ in which hydrogen peroxide, hydrogen, and oxygen $\left(\mathrm{H}_{2} \mathrm{O}_{2}, \mathrm{H}_{2}\right.$, and $\left.\mathrm{O}_{2}\right)$ will be introduced in concentrations predicted by the radiolysis code.

Water radiolysis simulations have been successfully performed using a computer program. This radiolysis code was obtained through Argonne National Laboratory (ANL) and has been updated to be compatible with the RPI VMS/VAX system. The concentrations of molecular species, $\mathrm{H}_{2} \mathrm{O}_{2}, \mathrm{H}_{2}$, and $\mathrm{O}_{2}$, produced during radiolysis are being used for laboratory solution modeling. The radiolysis code requires input of the radiolytic yields, or $G$ values for the species, a set of secondary reactions, initial concentrations, temperature and dose rates. G values $^{3}$ for gamma radiation and the secondary reactions ${ }^{3,4-7}$ were sbtained from the literature. Temperatures of 50,90 , and $130^{\circ} \mathrm{C}$ were used as input. Initial conditions for argon purging and for hydrogen purging were individually tested. The range of dose rates applied in the code was $10^{18}-10^{24} \mathrm{eV} / \mathrm{liter} / \mathrm{sec}$. This range included the experimentally determined values from the irradiated tests at the 
RPI Linear Accelerator $\left(10^{18}-10^{19} \mathrm{eV} / \mathrm{iter} / \mathrm{sec}\right.$ ) and published values for the NET Aqueous Lithium Salt Blanket design $\left(3.3 \times 10^{22} \mathrm{eV} / \text { iter/sec. }\right)^{8}$ Steady state concentrations (ppb) for $\mathrm{H}_{2} \mathrm{O}_{2}, \mathrm{H}_{2}$, and $\mathrm{O}_{2}$ are presented as a function of dose rate in Figures 5 through 9 . Dissolved $\mathrm{H}_{2}$ for the hydrogen purged system was maintained at approximately 1450 to $1500 \mathrm{ppb}$ for all simulations. The code was checked using published inputs and outputs from similar programs. Agreement was within $30 \%$ for argon-and hydrogen-purged simulations at $25^{\circ} \mathrm{C}$ and $3.12 \times 10^{22}$ $\mathrm{eV} /$ iter/sec. Better agreement, within 10\%, was seen with data from ANL in an argon-purged simulation at $90-100^{\circ} \mathrm{C}$ and $5 \times 10^{21} \mathrm{ev} /$ iter/sec.

As mentioned previously, $\mathrm{H}_{2} \mathrm{O}_{2}, \mathrm{H}_{2}$, and $\mathrm{O}_{2}$ will be introduced in laboratory solutions that are intended to model irradiated conditions during the next few months. The molecular species concentrations were obtained from the argonpurged simulation set, in the $10^{23}-10^{24} \mathrm{eV} /$ iter/sec. dose rate range. $\mathrm{Ar} / \mathrm{O}_{2}$ and $\mathrm{Ar} / \mathrm{H}_{2}$ gas mixtures have been prepared to yield the appropriate dissolved gas concentrations. $\mathrm{H}_{2} \mathrm{O}_{2}$ will be added periodically to balance out catalytic decomposition. ECP measurements will be made in short term tests. It is anticipated that $\mathrm{H}_{2} \mathrm{O}_{2}$ and $\mathrm{O}_{2}$ in solution will create a more oxidizing system and cause a noble (positive) ECP shift. Longer term SSRT tests may be performed with $\mathrm{H}_{2} \mathrm{O}_{2}, \mathrm{H}_{2}$, and $\mathrm{O}_{2}$ together. Alternately, SSRT tests may be run without $\mathrm{O}_{2}$, but with the ECP fixed at the potential which would be realized if $\mathrm{O}_{2}$ was present. The combination of sensitized metallurgical condition, environment, stress and oxidizing potential may act to cause intergranular cracking in $316 \mathrm{SS}$ as seen in Type 304 stainless steel. ${ }^{9}$ 


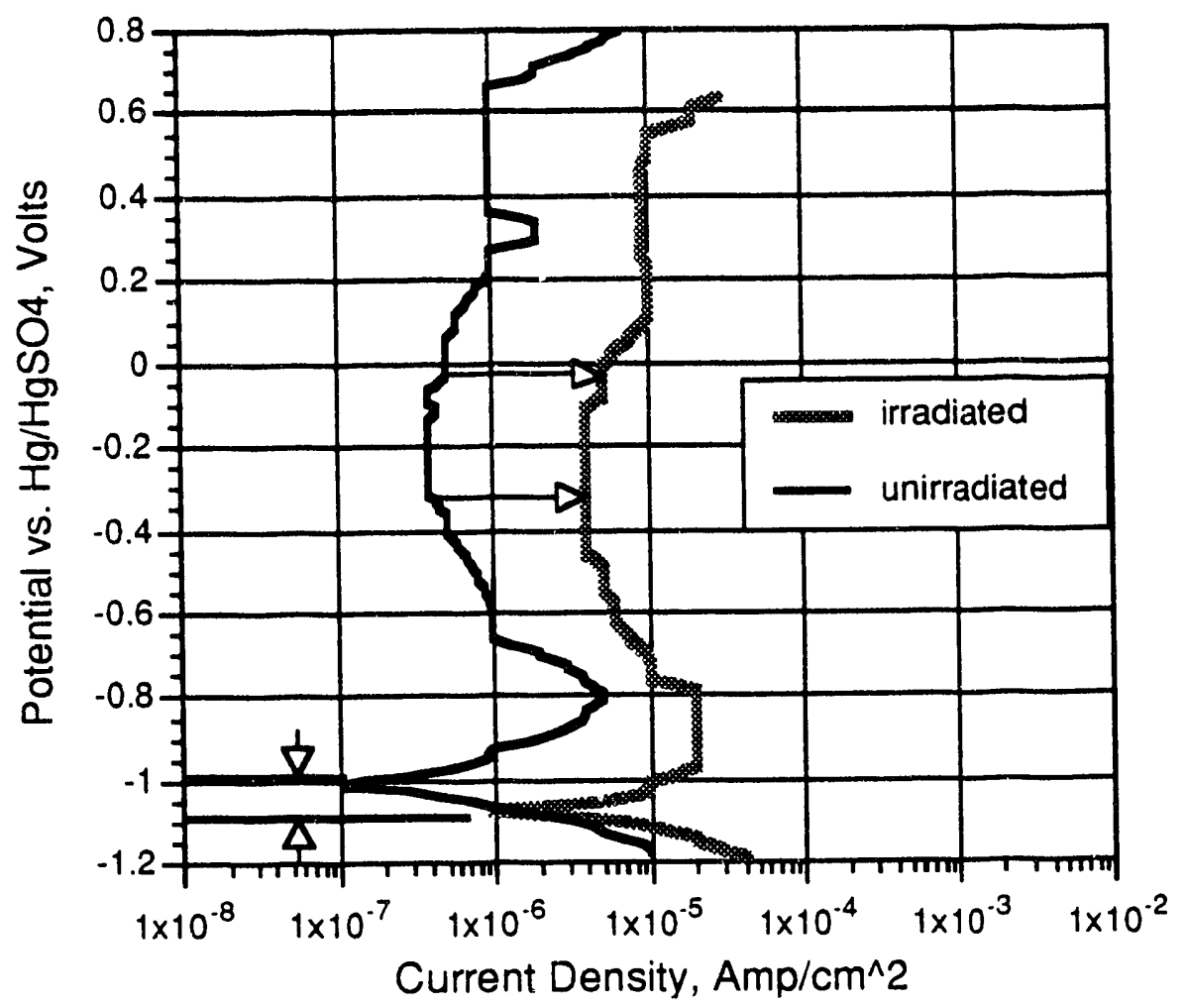

Figure 1. Potentiodynamic polarization curves for 316SS in hydrogen deaerated pure water, exhibiting active shift in the zero current potential and nearly an order of magnitude increase in passive current density for irradiated versus un-irradiated solutions. 


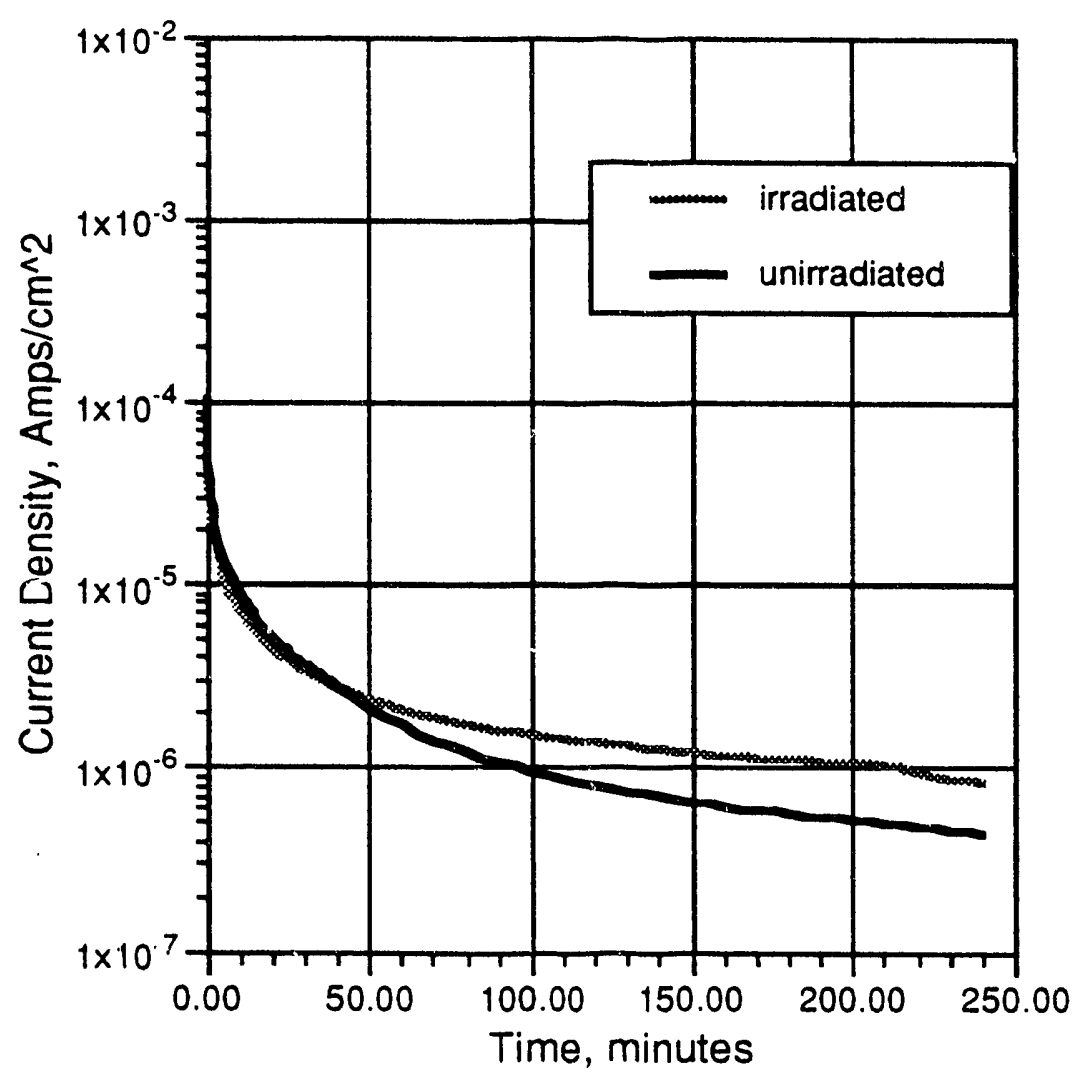

Figure 2. Passive current density of solution annealed Type 316 SS as a function of time, in irradiated and un-irradiated solutions. Specimen held at a potential of $-0.270 \mathrm{~V} \mathrm{Hg} / \mathrm{HgSO} 4$, in $0.0005 \mathrm{M} \mathrm{K} 2 \mathrm{SO} 4$. 


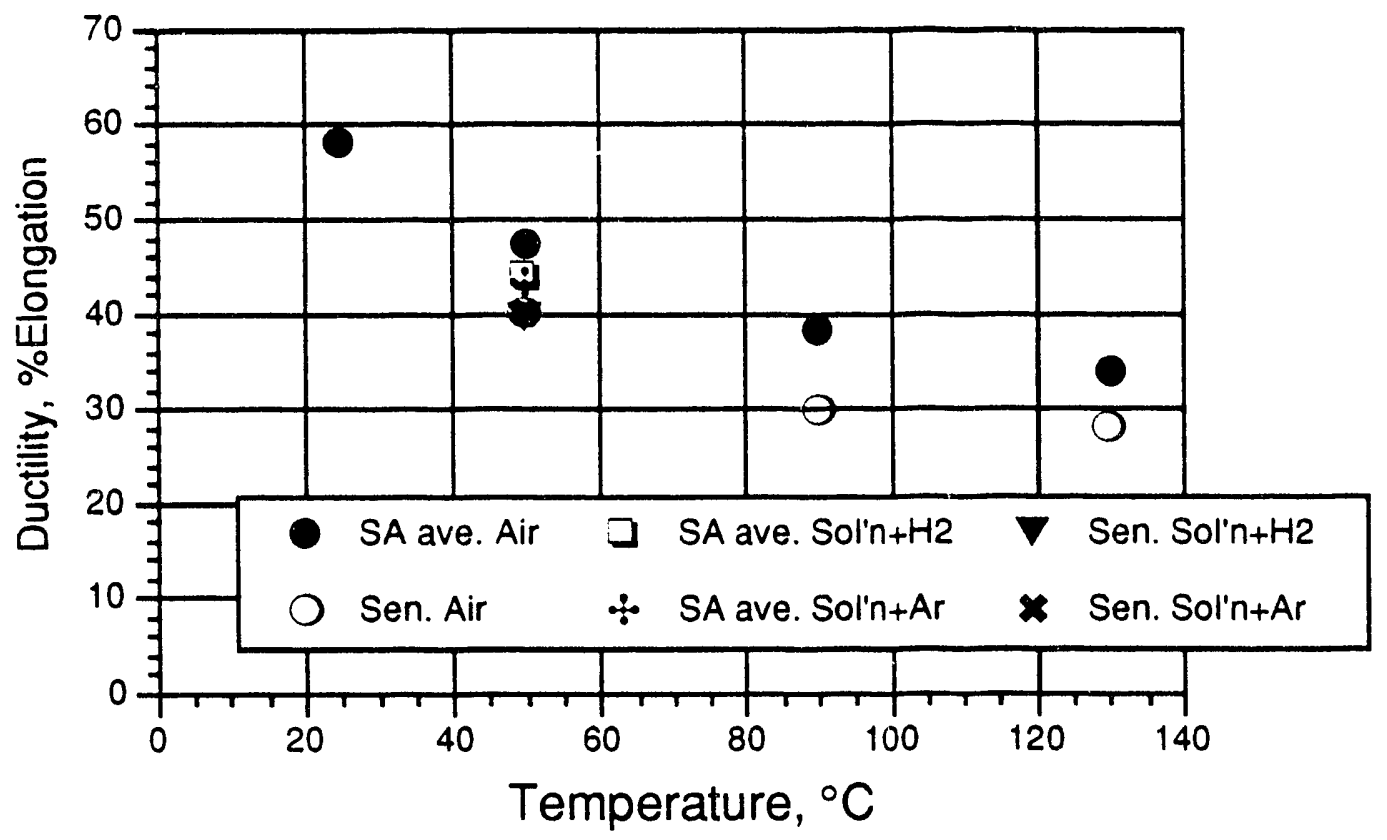

Figure 3. Ductility as a function of temperature for solution annealed (SA) and sensitized (Sen.) Type 316 SS: 1) in air and 2) in 0.0005M K2SO4, deaerated with either hydrogen or argon gas.

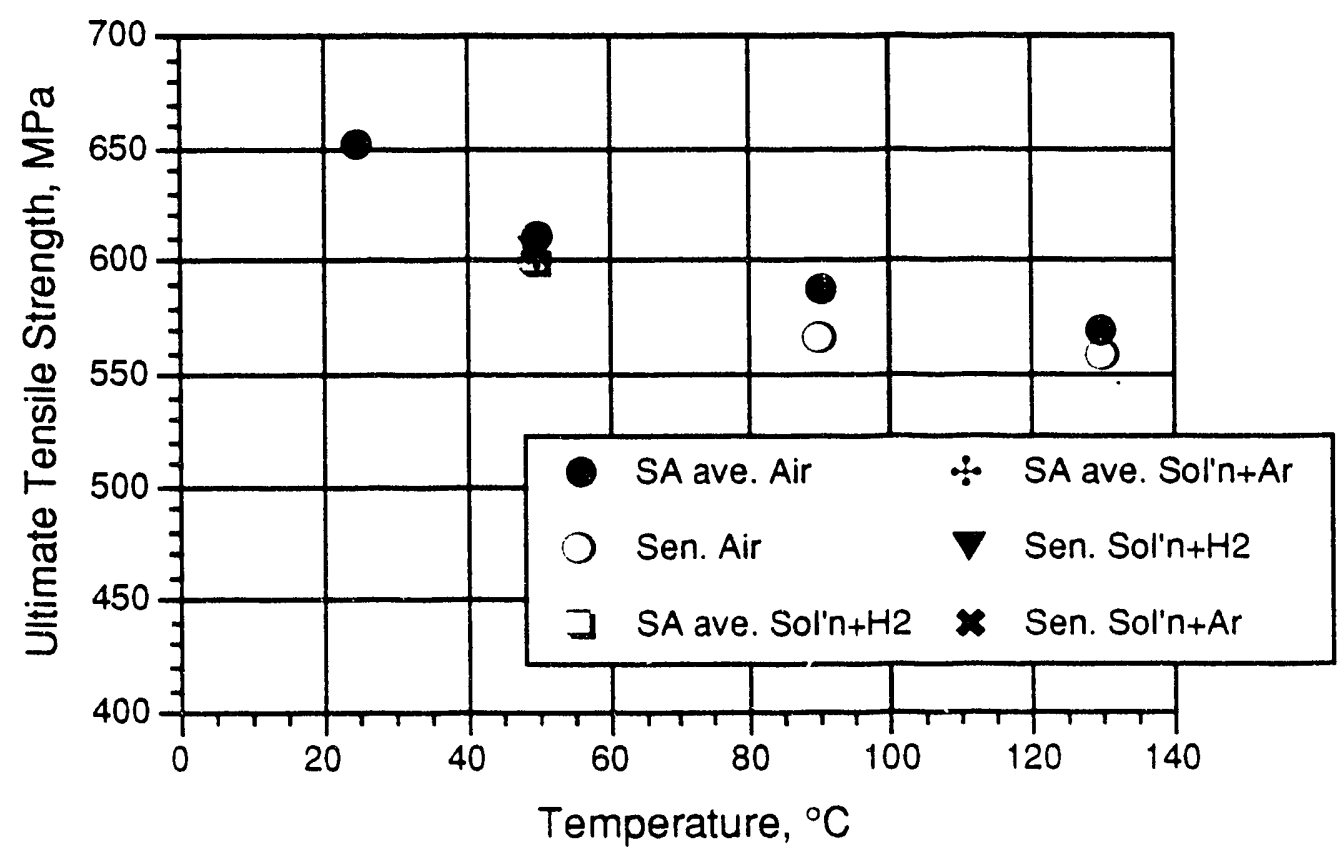

Figure 4. Ultimate Tensile Strength as a function of temperature for solution annealed (SA) and sensitized (Sen.) Type 316 SS: 1) in air and 2) in 0.0005M $\mathrm{K} 2 \mathrm{SO} 4$, deaerated with either hydrogen or argon gas. 


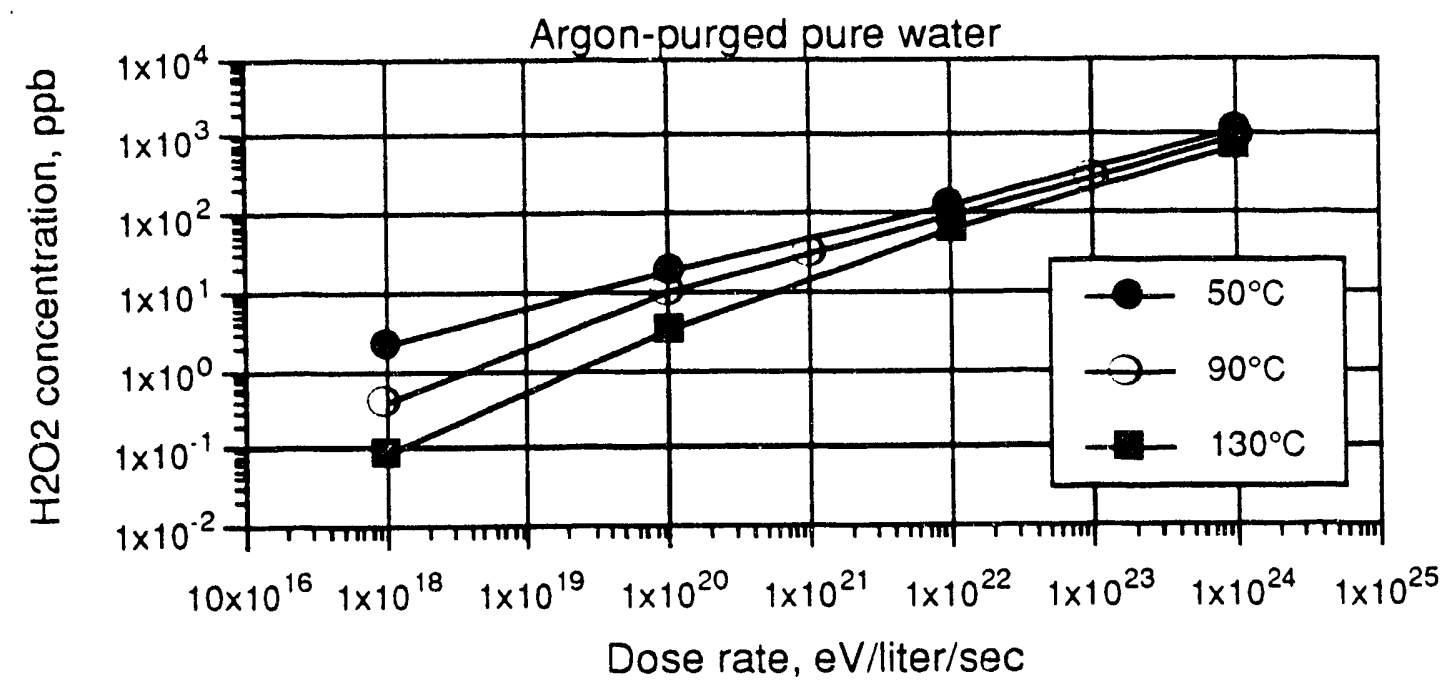

Figure 5. Steady state hydrogen peroxide concentration as a function of dose rate in a radiolysis computer simulation. Argon-purged pure water at 50, 90, and $130^{\circ} \mathrm{C}$.

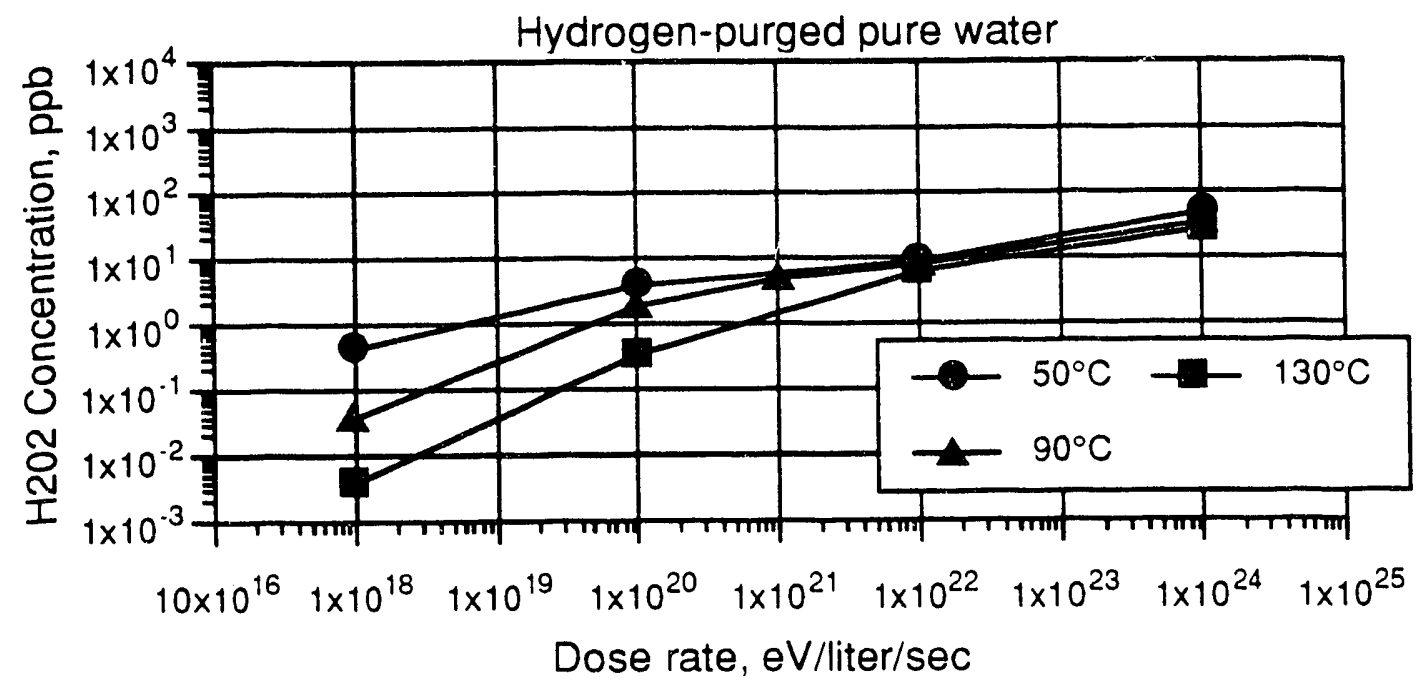

Figure 6. Steady state hydrogen peroxide concentration as a function of dose rate in a radiolysis computer simulation. Hydrogen-purged pure water at 50,90, and $130^{\circ} \mathrm{C}$. 


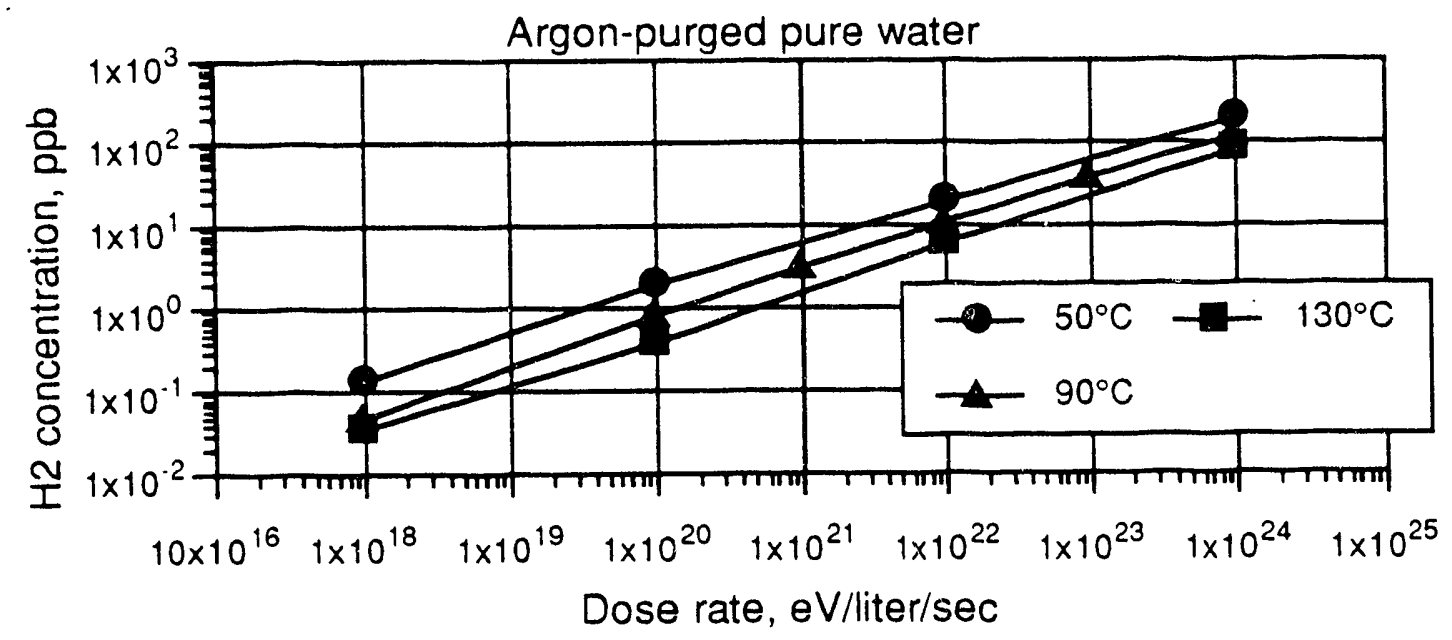

Figure 7. Steady state dissolved hydrogen concentration as a function of dose rate in a radiolysis computer simulation. Argon-purged pure water at 50, 90, and $130^{\circ} \mathrm{C}$.

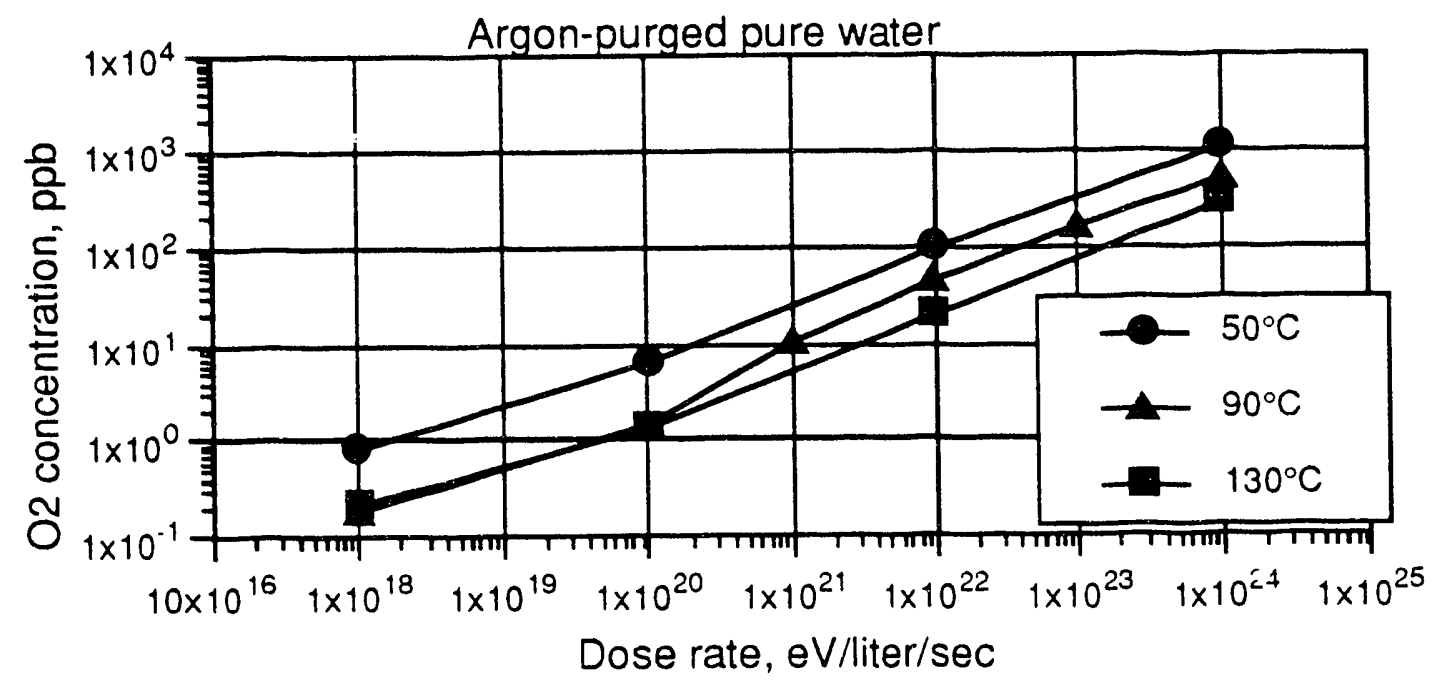

Figure 8. Steady state dissolved oxygen concentration as a function of dose rate in a radiolysis computer simulation. Argon-purged pure water at 50,90 , and $130^{\circ} \mathrm{C}$. 


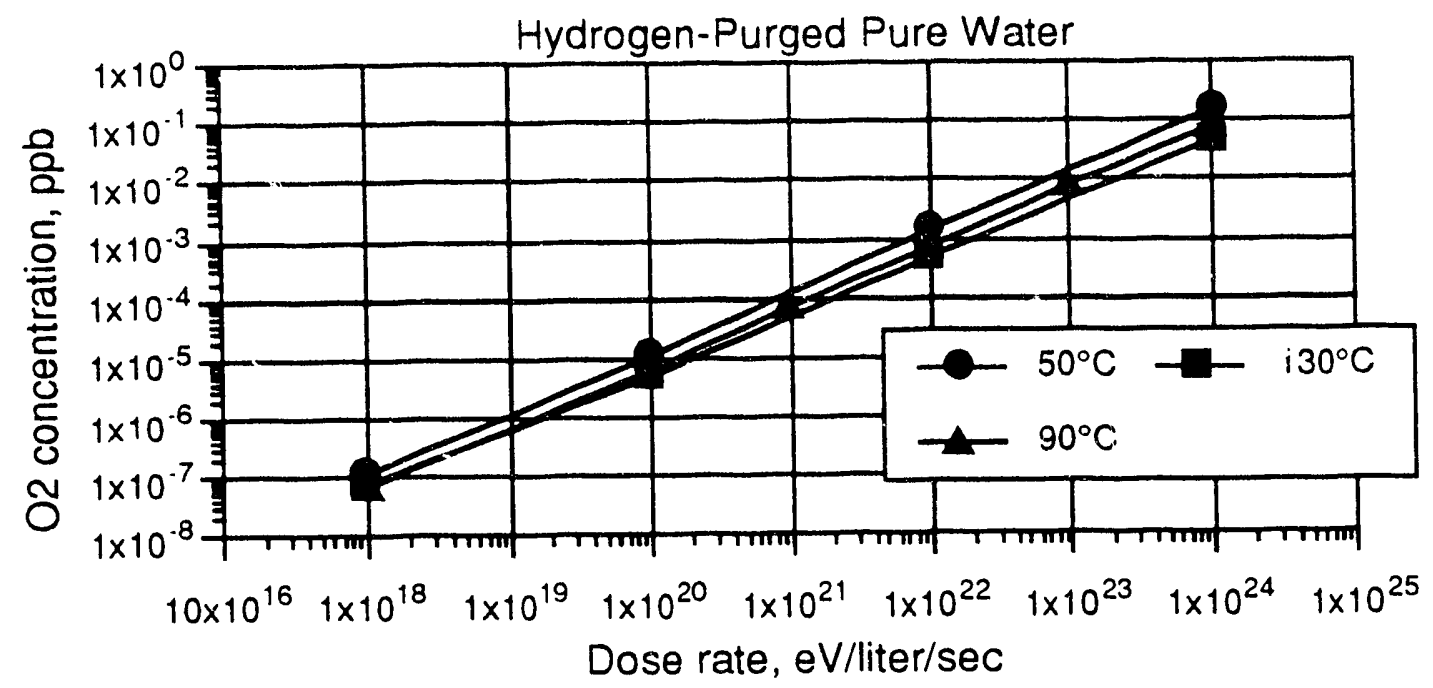

Figure 9. Steady state dissolved oxygen concentration as a function of dose rate in a radiolysis computer simulation. Hydrogen-purged pure water at 50, 90, and $130^{\circ} \mathrm{C}$. 


\section{RROPOSED PROGRAM FOR YEAR TWO OF PROJECT}

Electrochernical polarization experiments will be continued on 316 stainless steels in both non-irradiated and irradiated test solutions as a function of temperature $\left(50^{\circ} \mathrm{C}-130^{\circ} \mathrm{C}\right)$. For the non-irradiated cases, the solution chemistries will be pure water (doped with $0.0005 \mathrm{M} \mathrm{K}_{2} \mathrm{SO}_{4}$ ), used as a reference, and solutions prepared according to the radiolysis codes developed by ANL. In addition, a recirculating test loop, capable of obtaining "grab" samples will be constructed in order to determine the $\mathbf{s}$ - anfic chemistries developed by irradiation of the aqueous solution from the linear accelerator. In particular, concentration of dissolved oxygen, hydrogen, peroxide, as well as $\mathrm{pH}$, conductivity and temperature will be measured. An attempt will be made to determine dissolved ionic species as well as suspended solid reaction products. However, it is likely that these concentrations will be so small that accurate determination will not be possible. In each case, reference experiments will be performed on platinum in order to determine if measured shifts in open circuit potentials and increases in current densities are associated with actual increases in corrosion rates, or only due to oxidation of chemical species produced by radiolysis. Initially experiments will be performed under hydrogen water chemistry (HWC) conditions since electrochemical me asurements are simplified under these conditions. Future experiments will also be performed under normal water chemistry (NWC) conditions.

In every case laboratory experiments will be performed in non-irradiated solutions whose chemistry is modeled by the ANL radiolysis code in order to differentiate between the intrinsic effects of irradiation and those associated with chemical changes in the solutions due to radiation. 
Metallurgical conditions of the 316SS will include solution annealing, sensitization and cold working of the base alloy, as well as evaluating the effects of autogenous welding on the general corrosion behavior.

Slow strain rate stress corrcsion cracking tests will be initiated in pure water as well as in solutions prepared according to the ANL codes for irradiated pure water. The principal variables to be examined in the stress corrosion cracking (SCC) tests will include electrochemical potential, temperature and the metallurgical condition of the alloy. The primary emphasis in the SCC experiments will be to determine the role of the variables of interest on crack initiation since ANL is developing a program to determine the effects of these variablies on crack propagation rates. Electrochemical potential is a particularly important variable since the experiments performed may determine the "critical" potentials for "safe" operation of a reactor without fear of stress corrosion cracking, and may establish the water chemistry criteria which must be maintained.

Corrosion fatigue tests also will be performed, primarily utilizing the environmental and metallurgical variables described for the SCC tests. In addition, test frequency will be examined in these regions: (a) at $10 \mathrm{~Hz}$ to simulate high frequency low amplitude load levels during reactor steady-state operation; (b) at $0.1 \mathrm{~Hz}$ to simulate thermally generated stresses caused by on-off cycles of the reactor; and (c) for a superposition of high-cycle, low-amplitude loads on lower cycle, higher amplitude loads to simulate high and low power demand cycles on the reactor. As with the SCC tests, the primary emphasis of the corrosion fatigue (CF) tests will be to examine the effects of a typical ITER environment on crack initiation since ANL has proposed performing appropriate crack propagation experiments. 
It should perhaps be noted that, in all of the experiments proposed, the goal of the program is not only to determine the corrosion rates, SCC and CF susceptibilities of 316SS under expected ITER conditions, but also to determine the boundary conditions for potential ITER operation. For example, it is possible that the critical potential range for the initiation of stress corrosion cracks will be well outside of the electrochemical potential range anticipated under "normal" operating conditions. However, a determination of the critical potential (if it exists) will allow the determination of a set of electrochemical boundary conditions which will allow the avoidance of environmental cracking, as well as allow an understanding of the system under "upset" conditions.

\section{DISCLAIMER}

This report was prepared as an account of work sponsored by an agency of the United States Government. Neither the United States Government nor any agency thereof, nor any of their employees, makes any warranty, express or implied, or assumes any legal liability or responsibility for the accuracy, completeness, or usefulness of any information, apparatus, product, or process disclosed, or represents that its use would not infringe privately owned rights. Reference herein to any specific commercial product, process, or service by trade name, trademark, manufacturer, or otherwise does not necessarily constitute or imply its endorsement, recommendation, or favoring by the United States Government or any agency thereof. The views and opinions of authors expressed herein do not necessarily state or reflect those of the United States Government or any agency thereof. 

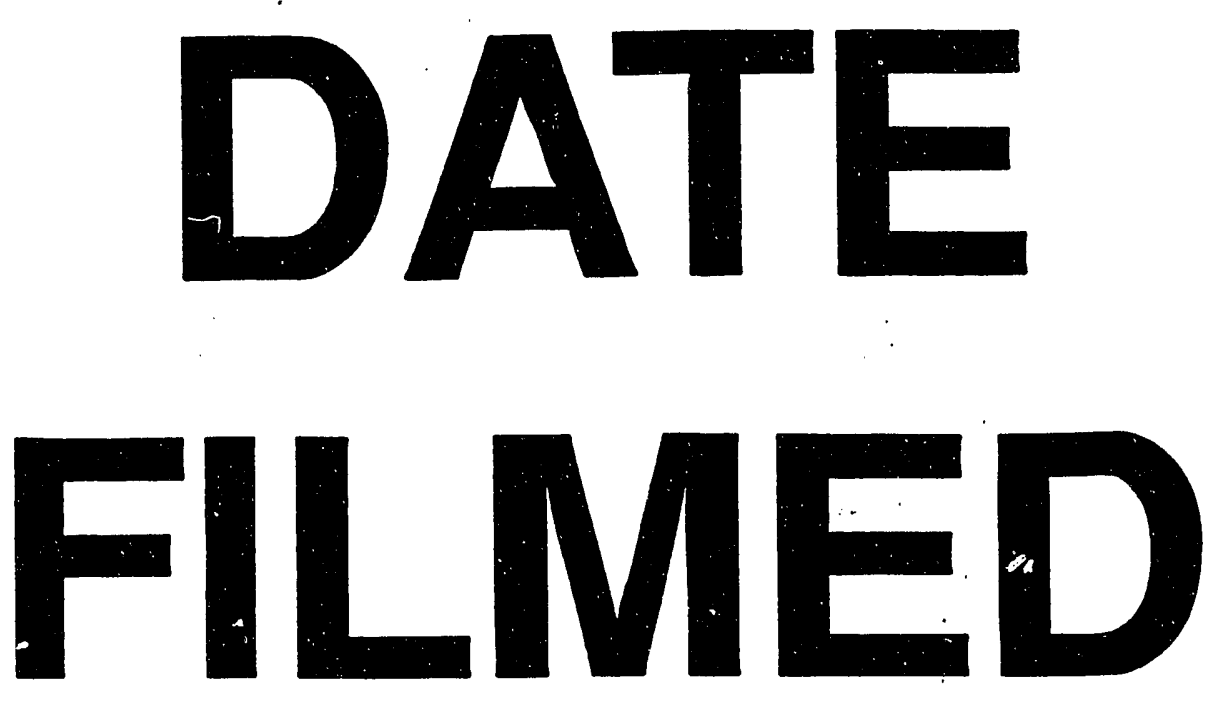

$9 / 23 / 93$
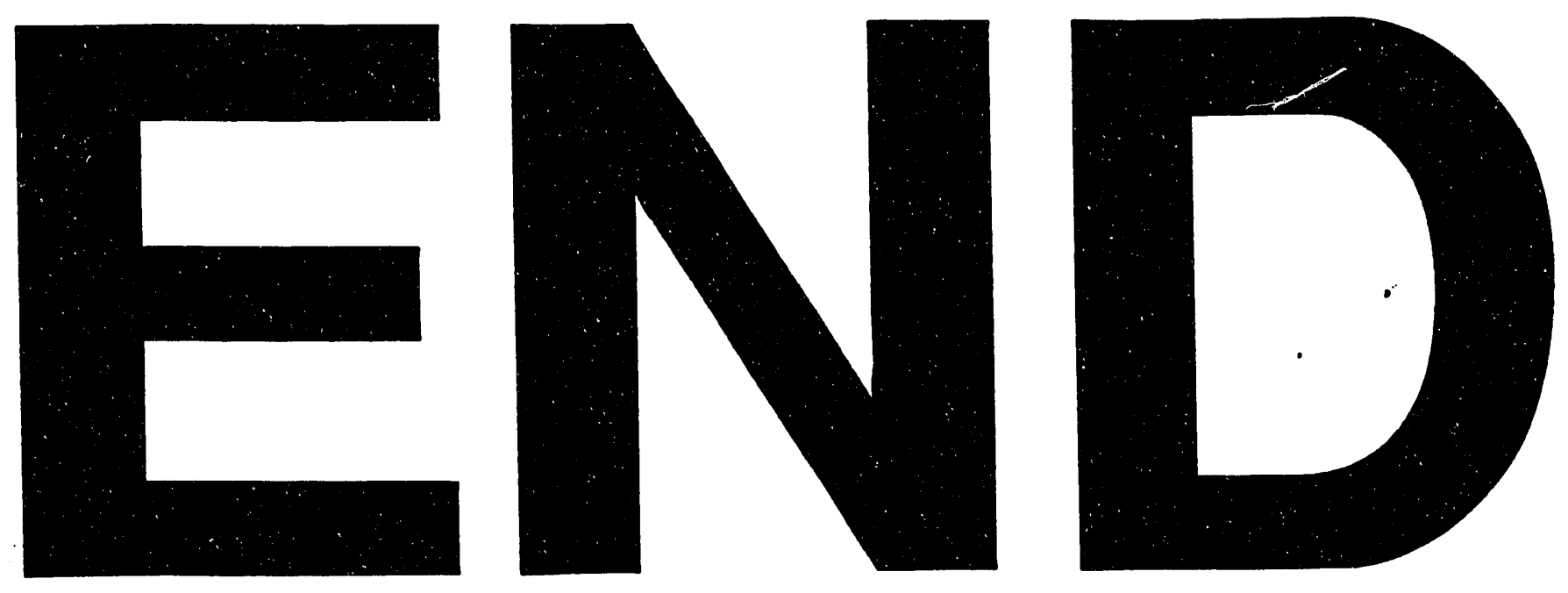
